\title{
Label changes conflict with WHO sugar advice
}

$\mathrm{D}$ id you enjoy a cup of orange juice with breakfast this morning? Congratulations! You've already blown your sugar allowance for the day.

Ideally, less than $5 \%$ of a person's daily calories should come from sugar, according to new World Health Organization (WHO) guidelines on sugars intake for adults and children. That amounts to just 25 grams of the sweet stuff - about as much in a single cup of $\mathrm{OJ}$ - for adults on a typical 2000 calorie-per-day diet. There is wiggle room for a second cup of juice with lunch, though. WHO's previous recommendation, that a maximum sugar intake of no more than $10 \%$ of daily calories reduces the risk of overweight, obesity and tooth decay, still stands. What's new is the suggestion that a further reduction could be even more beneficial. "Unfortunately, in the last 10 years we've

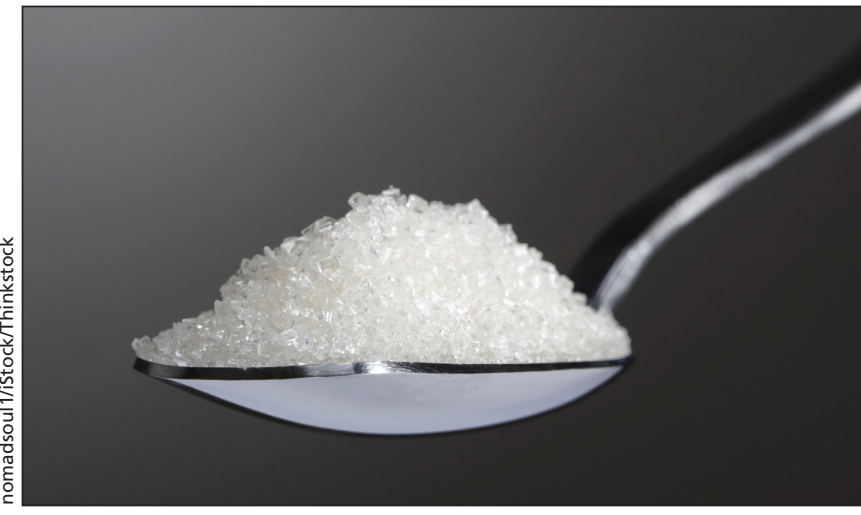

Health Canada may need to rethink proposed food labelling changes in light of new WHO sugar intake guidelines. seen an almost universal increase in the per capita consumption of sugar," says Dr. Francesco Branca, WHO director of nutrition for health and development. "There's basically nowhere complying with that $10 \%$."

Canadians may have to cut their intake by a least half to achieve health benefits. According to Statistics Canada, we consume an average $110 \mathrm{~g}$ or the equivalent of 26 teaspoons of sugar a day, accounting for $21.4 \%$ of the total calories in our diet.

However, Branca says that it's important to distinguish between "intrinsic sugars" - those that are naturally built into whole foods like milk, fruit and vegetables - and what WHO calls "free sugars" - those added to foods and beverages, and present in caloriedense sweeteners like honey, syrup and fruit juice.

The new WHO recommendations apply only to free sugars. There's no evidence of negative health effects from consuming intrinsic sugars, says Branca.
"Making policy changes to support this will be key if countries are to live up to their commitments to reduce the burden of noncommunicable diseases."

Bill Jeffery, national coordinator for the Canadian branch of the Centre for Science in the Public Interest, says the advice is timely given that Health Canada is overhauling the way food and drink labels present information about sugar.

that benchmark, foods that I think most Canadians would consider to be sweets or candy don't look so bad."

According to Branca, targets for total sugar don't make sense for populations that get most of their dietary sugar from processed food and sweetened beverages, and may discourage people from eating fresh fruit and vegetables.

In a statement to $C M A J$, Health Canada said that the proposed daily value "is not a recommended level of intake, but a useful benchmark that would help people assess the relative amount of sugars in a product." Used in this way, "most foods identified as having a lot of sugars ... would be foods containing free sugars."

The agency also stated that "following the healthy pattern of eating in Canada's Food Guide will result in a lower intake of free sugars." Currently, no countries spe-

Currently, Health Canada doesn't provide specific recommendations about how much sugar Canadians should consume. But last year, the department proposed including a line on the nutrition facts tables for "added sugars," and establishing a $100 \mathrm{~g}$ "daily value" for total sugar intake.

Although a step in the right direction, these measures will need reworking to support the kind of reductions recommended by WHO, says Jeffery. For example, Health Canada's definition of added sugar won't include some free sugars like fruit juice. "So a cup of juice that contains $28 \mathrm{~g}$ of free sugar more than half the maximum daily intake recommended by WHO could be labelled as having zero grams of added sugar," explains Jeffery.

$\mathrm{He}$ also questions the wisdom of setting a daily value for sugar based on an intake of $100 \mathrm{~g}$. "That's double or quadruple what WHO is recommending for free sugars," says Jeffery. "Against cifically list free sugars on food or beverage labels.

The food industry, for its part, criticized the evidence for reducing sugar intake below $5 \%$ of total calories. "By WHO's own definition there was low quality levels of evidence," says Phyllis Tanaka, vice president of scientific and regulatory affairs at Food \& Consumer Products of Canada.

The 5\% recommendation is based on a reanalysis of data from the 1940 s on the effect of wartime rationing on tooth decay. It's otherwise difficult to find large enough populations consuming low enough levels of sugar to conduct meaningful research, explains Branca. "Having some data pointing to an additional health benefit, WHO should make recommendations whenever possible; in this case, that's what WHO tried to do, instead of doing nothing." - Lauren Vogel, CMAJ 